\title{
Scurvy: A Rare Cause of Anemia
}

Frank R. Ricaurte ${ }^{1}$, Tariq Kewan ${ }^{2}$, Hamed Daw ${ }^{3}$

1. Westlake High School, Cleveland, USA 2. Internal Medicine, Cleveland Clinic - Fairview Hospital, Cleveland, USA 3. Hematology and Oncology, Cleveland Clinic - Fairview Hospital, Cleveland, USA

Corresponding author: Frank R. Ricaurte, fricaurte@me.com

\section{Abstract}

Scurvy is a rather uncommon disease today, and its symptoms can certainly be exhibited with vitamin C deficiency. Dangerously low levels of the vitamin can cause serious health complications and have been proven to be fatal. We present the case of a 42-year-old female with multiple primary diagnoses: easy bruising and Raynaud's syndrome without gangrene. The purpose of this report is to call attention to the clinical presentation, diagnosis, and treatment of scurvy.

Categories: Internal Medicine, Preventive Medicine

Keywords: scurvy, anemia, vitamin c supplementation, deficiency, perifollicular, hemorrhage

\section{Introduction}

The manifestation of scurvy comes from a lack of vitamin C, indicating that patients with the condition do not consume a sufficient amount of the vitamin in their diets [1]. After one to three months of inadequate vitamin C levels, scurvy leads to a myriad of different symptoms, including anemia, myalgia, bone pain, easy bruising, swelling, hemorrhages, corkscrew hairs, gum disease and gum bleeding, poor wound healing, mood changes, and depression [2]. The disease presents itself in four relatively distinct stages, phases of progression that exhibit increasingly severe symptoms [3]. Early treatment of the disease is essential for regulating the initial symptoms. This primarily entails replenishing vitamin $\mathrm{C}$ levels whether it be through a healthier diet of fruits and vegetables or through vitamin C supplements [4].

\section{Case Presentation}

A 42-year-old female presented with easy bruising and petechiae to her primary care physician and was thus transferred to hematology (Figure 1). Her medical history included chronic obstructive pulmonary disease (COPD), gastroesophageal reflux disease (GERD), human papillomavirus (HPV), mitral valve prolapse (MVP), acute pyelonephritis, anxiety, asthma, essential hypertension, hyperlipidemia, hyperthyroidism, migraines, nephrolithiasis, and obstructive sleep apnea (OSA). The patient has been smoking a half pack of cigarettes daily for the past 10 years. During her office visit, her humoral survey revealed that she had specific antibodies reflecting non-protective titers against the pathogenic bacterium, Haemophilus, and diphtheria-

Received 08/26/2019 Review began 09/02/2019 Review ended 09/13/2019 Published 09/18/2019

\section{() Copyright 2019}

Ricaurte et al. This is an open access article distributed under the terms of the Creative Commons Attribution License CC-BY 3.0., which permits unrestricted use, distribution, and reproduction in any medium, provided the original author and source are credited. tetanus. The reasons for the said visit included medication follow-up, vitamin level check, urinary urgency, and urinary frequency. These visit overviews reflect the attention given to the patient's symptoms and survey results. 


\section{Cureus}

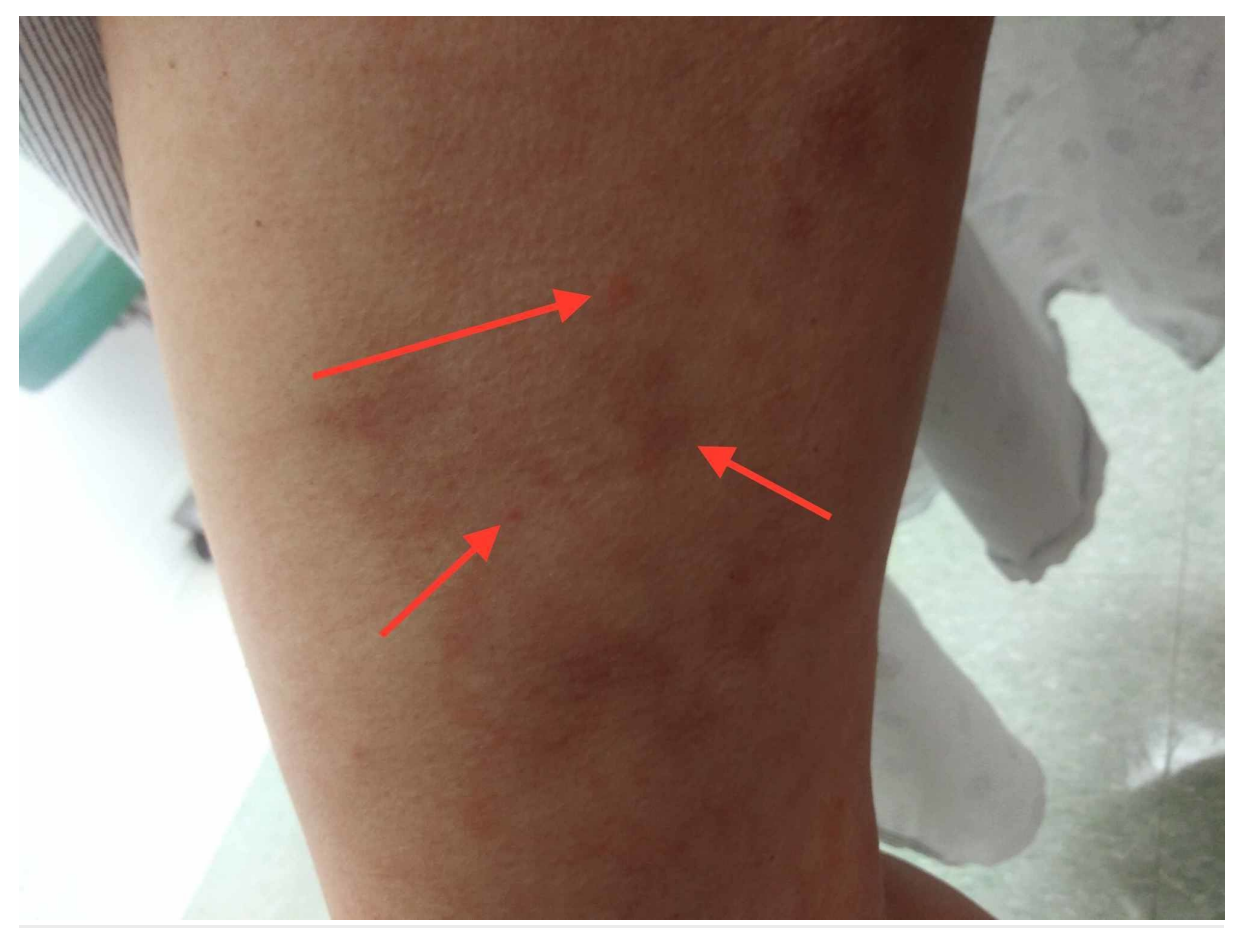

FIGURE 1: Anterior right arm with petechiae and microhemorrhages around the hair follicles

The patient had multiple vitamin deficiencies, vitamin C being the most notable of them; her vitamin C count as of December 2018 was 22 umol/L, below what is deemed a healthy amount. However, the patient's physical examination revealed perifollicular hemorrhage, petechiae, and bruising on various parts of the body (Figure 2). 


\section{Cureus}

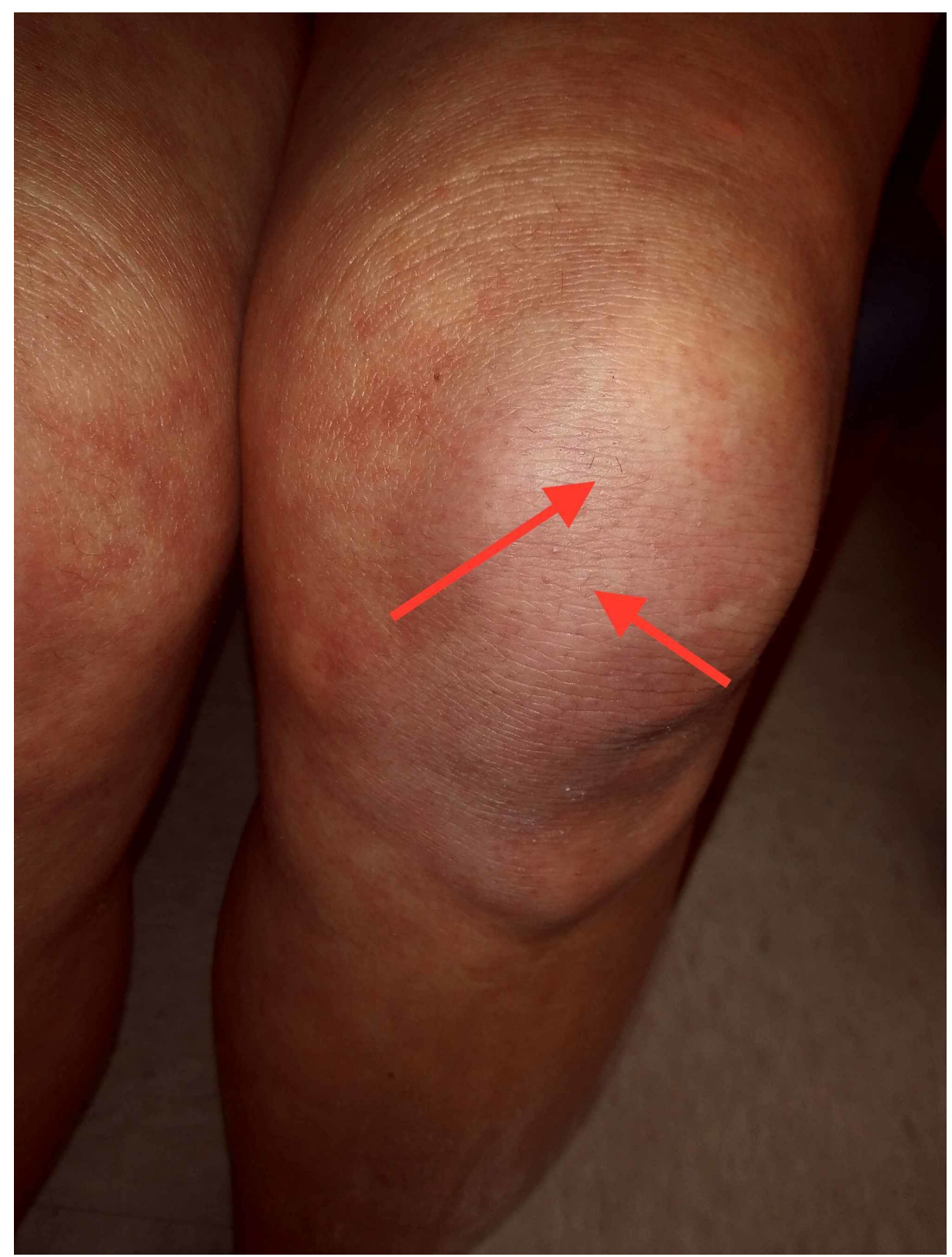

\section{FIGURE 2: Left lower extremity with anterior perifollicular hemorrhages}

\section{Discussion}

Scurvy is a disease caused by vitamin C deficiency, a deprivation that today has a prevalence of around 10 to $14 \%$ in adults [5]. The disease's rather low prevalence is quite plausibly a result of the many ways people can obtain adequate amounts of nutrients and vitamins today. Scurvy predominantly presents itself in individuals who abuse drugs and alcohol, live in conditions that prevent proper vitamin nourishment, or have a subpar dietary intake [6]. The overview of water-soluble vitamins written by Pazirandeh and Burns in February 2019 is referenced through the following information [7]. To be more precise regarding what level of vitamin C triggers the manifestation of scurvy's symptoms, "the plasma concentration of ascorbic acid is most commonly below $0.2 \mathrm{mg} / \mathrm{dL}$ under such conditions." Vitamin C has also been allocated to another notable medical purpose: the prevention of cardiovascular disease and cancer. Despite the evident benefits of vitamin C supplementation, there can be several side effects of such treatment, such as causing falsenegative stool guaiac results, diarrhea, abdominal bleeding, and increased chances of kidney stones. Hence, vitamin C supplementation is not always widely recommended as an everyday regimen and should only be adhered to in instances where the symptoms of scurvy clearly present themselves.

The patient, in this case, presented with a multitude of symptoms caused by vitamin C deficiency. The initial symptoms of scurvy patients can vary depending on the context of the patient's situation. Some patients may present with more extreme symptoms, such as hemorrhagic diathesis, although many patients show initial symptoms of anemia, perifollicular hemorrhages, bruising, and pain in upper and lower 
extremities, as presented in this case [8-9].

Diagnosing a patient with scurvy involves precarious methods of identification. Laboratory tests are not always effective in making a scurvy diagnosis certain. "Plasma ascorbic acid level may help in establishing the diagnosis, but this level tends to reflect the recent dietary intake rather than the actual tissue levels of vitamin C. Signs of scurvy can occur with low-normal serum levels of vitamin C [3]. Recognizing the history of patients' vitamin $\mathrm{C}$ deficiency in regards to their dietary intake and, more specifically, their tissue level data leads to a more accurate diagnosis of scurvy.

Unlike scurvy's past treatment efforts that were often futile as per the disease's extremely high mortality rate, scurvy today is surely treatable. The current treatment is rather straightforward as, in most cases, it consists of standard vitamin $\mathrm{C}$ supplementation. The amount given to patients typically decreases within a few weeks of the original given dosage $[2,10]$. The starting amount obviously depends on the severity of the disease at the time of the diagnosis, but the gradual decrease in dosage over time is proven to steadily lessen symptoms of the disease. Identifying the disease, which primarily is accomplished by means of recognizing petechiae, perifollicular hemorrhage, and bruising, is most influential in the primary dosage given to patients; severity increases over the time during which the deficiency is sustained. After a few months of supplementation, patients' vitamin levels are typically in accordance with the recommended dietary allowance (RDA). Commonly targeted in many scurvy cases, vitamin C therapy is used to replete the body with a proper dietary plan and vitamin C supplements [8-9].

\section{Conclusions}

This case emphasizes the recognition required to identify scurvy and the potential consequences that would result if its diagnosis was otherwise not made. Some symptoms of the presented patient, namely petechiae, were certainly more subtle than the more extreme instances of scurvy's symptoms in other cases.

Nevertheless, this case's presentation of scurvy and its subsequent remission still remain valuable in aiding the proper handling of the disease. The treatment of scurvy discussed should be used with reference to the relativity of each patient's severity of symptoms, along with the disease's progression.

\section{Additional Information}

\section{Disclosures}

Human subjects: Consent was obtained by all participants in this study. Conflicts of interest: In compliance with the ICMJE uniform disclosure form, all authors declare the following: Payment/services info: All authors have declared that no financial support was received from any organization for the submitted work. Financial relationships: All authors have declared that they have no financial relationships at present or within the previous three years with any organizations that might have an interest in the submitted work. Other relationships: All authors have declared that there are no other relationships or activities that could appear to have influenced the submitted work.

\section{References}

1. Scurvy. (2019). Accessed: May 29, 2019: http://rarediseases.info.nih.gov/diseases/10406/scurvy.

2. Léger D: Scurvy: reemergence of nutritional deficiencies. Can Fam Physician. 2008, 54:1403-406.

3. Scurvy and Vitamin C - Food and Drug Law . (2004). Accessed: May 30, 2019: http://dash.harvard.edu/bitstream/handle/1/8852139/Mayberry.html?sequence=2.

4. Scurvy Treatment \& Management. (2017). Accessed: May 29, 2019: http://emedicine.medscape.com/article/125350-treatment.

5. Velandia B, Centor RM, McConnell V, Shah M: Scurvy is still present in developed countries . J Gen Intern Med. 2008, 23:1281-84. 10.1007/s11606-008-0577-1

6. Lux-Battistelli C, Battistelli D: Alcohol withdrawal: possible risk of latent scurvy appearing as tiredness: a STROBE-compliant study. J Clin Med Res. 2019, 11:26-34. 10.14740/jocmr3643

7. Overview of Water-soluble Vitamins. (2019). Accessed: May 29, 2019: http://www.uptodate.com/contents/overview-of-water-soluble-vitamins.

8. Baradhi KM, Vallabhaneni S, Koya S: Scurvy in 2017 in the USA . Proc (Bayl Univ Med Cent). 2018, 31:22728. 10.1080/08998280.2018.1435115

9. Hahn T, Adams W, Williams K: Is vitamin C enough? A case report of scurvy in a five-year-old girl and review of the literature. BMC Pediatr. 2019, 19:74. 10.1186/s12887-019-1437-3

10. Wang AH, Still C: Old world meets modern: a case report of scurvy . Nutr Clin Pract. 2007, 22:445-48. 10.1177/0115426507022004445 